\title{
Characteristics of Soil and Water Loss Based on Runoff Plot
}

\author{
Zhao-Wei Shen ${ }^{1 a}$, Fang-Chun Luª, Li Gang²a \\ ${ }^{1}$ Zhejiang Key Laboratory of Water Conservancy Disaster Prevention and Reduction, Zhejiang \\ Institute of Hydraulics \& Estuary ,Hangzhou ,310020,China \\ 2Zhejiang Guang Chuan Engineering Consulting Co., Ltd. ,Hangzhou ,310020,China \\ a656375320@qq.com
}

\begin{abstract}
Key words: soil and water loss; rainfall; runoff; sediment concentration
Abstract: This paper selects Zhejiang province 5 runoff plots of rainfall, runoff and sediment loss was studied. The results showed that: (1) the annual rainfall mainly concentrated in 4-9 months, accounted for $60.7 \%-66.6 \%$ of the annual rainfall. (2) the annual runoff is mainly concentrated in 5-9 months, which accounts for $67.4 \%-76.2 \%$ of annual runoff. The amount of sediment loss is mainly concentrated in 5-9 months, which accounts for $68.3 \%-86.7 \%$ of the annual runoff. (3) the results show that the runoff with rainfall fluctuations and fluctuations, the loss of sediment with the flow of the fluctuations in the flow, it shows that the runoff and rainfall, sediment loss and runoff are closely related.
\end{abstract}

\section{Introduction}

Soil erosion is one of the important environmental problems that endanger the ecological security, and it is one of the forms of ecological destruction, and it is also one of the main environmental problems that the society pays close attention to at the same time ${ }^{[1]}$.

Rainfall is one of the important factors causing soil and water loss ${ }^{[2,3]}$. The study of the relationship between rainfall and soil erosion is one of the important contents of soil and water conservation science, and it can provide scientific basis for the development of soil and water conservation project. Therefore, this research chooses Zhejiang province Anji, Yongkang, Changshan, Tiantai and Yuyao 5 runoff plots as the study area, the rainfall, runoff and sediment of various regions in 2015, analyses the relationship between rainfall and runoff, the runoff and sediment loss, soil erosion and provide scientific basis for.

\section{General Situation of Study Area}

This study includes Anji, Yongkang, Changshan, Yuyao, and the roof of the runoff area, the basic situation is as follows:

Anji County, Hutang comprehensive observation field belongs to the small watershed of lake pond, has become the national soil and water conservation science and technology demonstration park, park area $57.88 \mathrm{hm} 2$. According to the Anji County Xiaofeng meteorological station 1980 2009a daily rainfall data statistics, annual rainfall 1153 1864mm, 30A average rainfall $1480 \mathrm{~mm}$, the erosive rainfall more than

$12 \mathrm{~mm}$ accounted for $73.9 \%$ of rainfall, rainfall ratio of $6 \sim 8$ in each month were more than $10 \%$, the soil in the river basin is mainly in red and yellow soil, the main land use types for plantation. Yongkang street is a small watershed runoff Qiantang River basin. According to the Yongkang Municipal Meteorological Station of Yongkang 1980 2009a daily rainfall data statistics, annual rainfall $983 \sim 2134 \mathrm{~mm}, 30 \mathrm{~A}$ average rainfall $1428 \mathrm{~mm}$, the erosive rainfall more than $12 \mathrm{~mm}$ accounted for $71.3 \%$ of rainfall, rainfall ratio of $3 \sim 8$ in each month were more than $10 \%$, soil is mainly red soil and yellow soil.

Changshan runoff is Qiantang River basin Tianma small watershed. According to the Changshan Fangcun county meteorological station 1980 2009a daily rainfall data statistics, annual rainfall $1319 \sim 2724 \mathrm{~mm}, 30 \mathrm{~A}$ average rainfall $1858 \mathrm{~mm}$, the erosive rainfall more than $12 \mathrm{~mm}$ accounted for $78.3 \%$ of rainfall, rainfall ratio of $3 \sim 7$ in each month were more than $10 \%$, soil is mainly red soil and limestone soil. 
The runoff field of the Tai River is a small watershed in the Qian Tang River Basin. According to the daily rainfall data of 1980 2009a roof Tiantai county meteorological station statistics, annual rainfall $820 \sim 1728 \mathrm{~mm}, 30 \mathrm{~A}$ average rainfall $1333 \mathrm{~mm}$, the erosive rainfall more than $12 \mathrm{~mm}$ accounted for $72.2 \%$ of rainfall, rainfall ratio of 5 9 in each month were more than $10 \%$, the soil is mainly red soil and paddy soil.

Yuyao is a small watershed runoff Qiantang River Li zhou. According to the Yuyao Municipal Meteorological Station of Yuyao 1980 2009a daily rainfall data statistics, annual rainfall $921 \sim 1736 \mathrm{~mm}, 30 \mathrm{~A}$ average rainfall $1386 \mathrm{~mm}$, the erosive rainfall more than $12 \mathrm{~mm}$ accounted for $73.3 \%$ of rainfall, rainfall ratio of $6 \sim 9$ in each month were more than $10 \%$, soil is mainly red soil and paddy soil.

\section{Research Method}

The annual rainfall, runoff and sediment yield were collected in 2015. The rainfall collection device was measured using a simple artificial rainfall level measuring device is installed in the open space, built-in water storage equipment, indoor with rain gauge. According to the design and construction of soil and water conservation monitoring sites in our province, the runoff and sediment collected from the catchment area are set at the bottom of each runoff plot. The first grade runoff pool is provided with a "V" type flow weir, one of which connects the two stage runoff pool, and the two stage runoff pool is provided with a "V" type flow weir, which is connected with the three stage runoff pool. When the runoff runoff occurs when runoff first collected water tank set runoff pooled into a tank through the aqueduct level runoff pool, when runoff runoff pool level is larger than that of the tank capacity, runoff began a diversion, part of runoff is diverted to the two level runoff pool; if runoff continue to increase two, the runoff runoff pool is larger than that of the tank capacity, the beginning of the two grade runoff diversion, part two in the pool runoff runoff into three runoff pool.

\section{Rainfall Characteristics}

In Anji, Yongkang, Zhejiang, Changshan, Yuyao, and the roof of a total of 5 Regional Rainfall in 2015 for analysis, the results shown in Figure 1.

In 2015, the total amount of rainfall in 5 regions of Zhejiang province was between 1716.0-2834.5mm, and the amount of rainfall was abundant. As can be seen from Figure 1, rainfall showed a significant wave trend, rainfall mainly concentrated in 4-9 months, accounting for $60.7 \%-66.6 \%$ of the annual rainfall, reaching the maximum value in June and July. And there are significant differences in rainfall in 5 areas, the total rainfall is the largest in Yuyao, Changshan times, the roof, Yongkang and Anji relatively minimal. In addition, Changshan and Yuyao in June and July rainfall reached the maximum value, significantly higher than other regions.

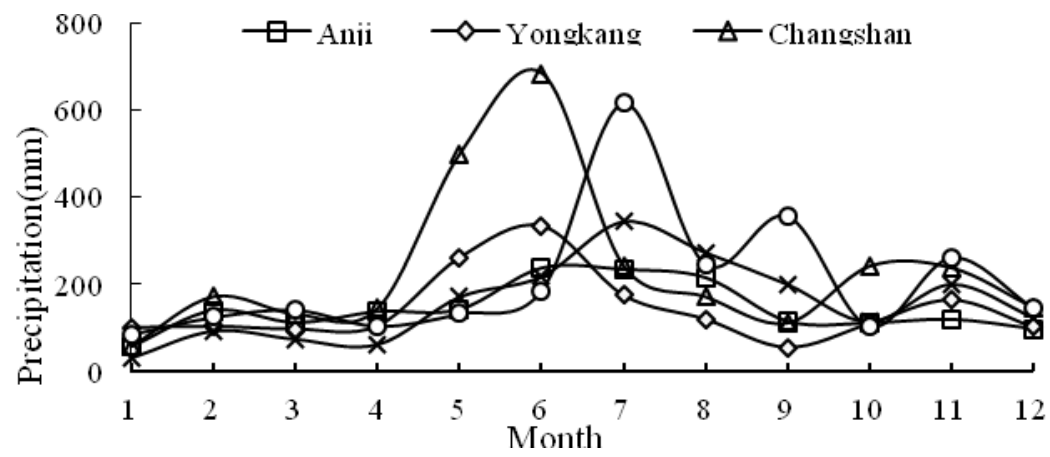

Fig.1 Monthly variation characteristics of rainfall in different regional

In the 4 quarter of 2015, the trend of rainfall was the same as that of the monthly rainfall, which showed a clear fluctuation trend. The precipitation in four seasons was the largest in the second and third quarter, the first and the fourth quarter was relatively small (Figure 2). And Yuyao and Yongkang are still in the second and third quarter reached the maximum value. 


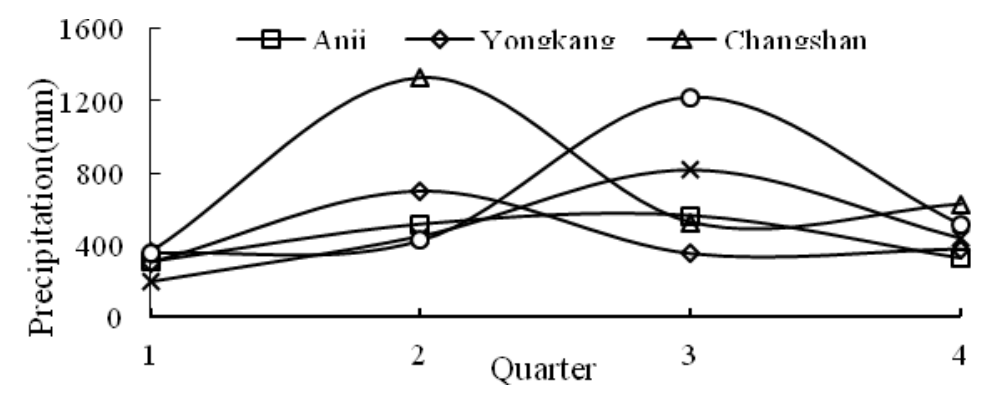

Fig.2 Seasonal variation characteristics of rainfall in different regions

\section{Characteristics of Soil and Water Loss}

From the 5 areas of monthly runoff situation (Figure 3), runoff showed obvious fluctuation trend. Runoff mainly concentrated in 5-9 months, accounted for $67.4 \%-76.2 \%$ of the annual runoff. The monthly runoff in Yuyao and Yongkang is still the largest, especially in the 5-9 month, directly determines how much of the two regions of the annual runoff, while Anji and Tiantai minimum. Runoff in autumn and winter seasons, the larger fluctuations in the spring, smaller fluctuations, and the spring and autumn and winter runoff is greater than the spring, which may have a certain relationship with the autumn and winter rainfall is greater than the spring.

From the 5 area monthly sediment loss situation (Figure 4), the amount of sediment losses showed obvious fluctuation trend. The amount of sediment loss is mainly

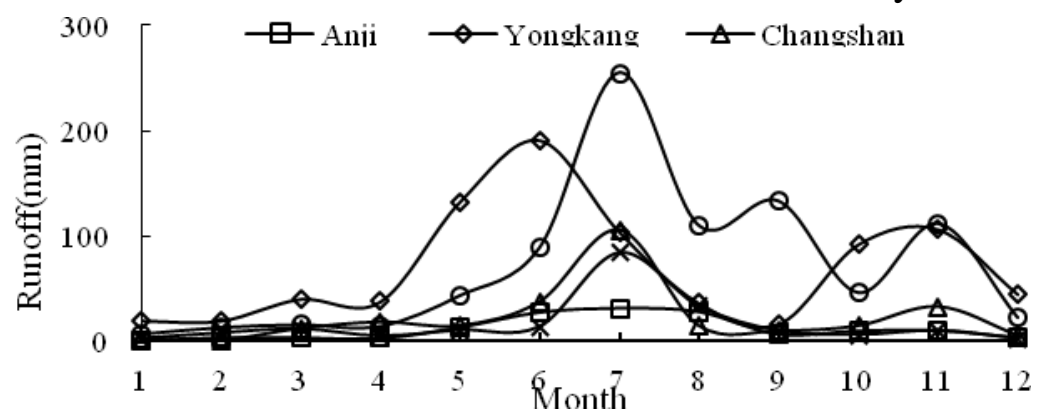

Fig.3 Monthly runoff depth in different regions

concentrated in 5-9 months, which accounts for $68.3 \%-86.7 \%$ of the annual runoff. The monthly sediment loss is mainly in Yuyao and Yongkang in the largest amount, the same as 5-9 in the runoff, directly determines the two annual sediment loss amount, while Anji and Tiantai minimum. The amount of sediment loss in autumn and winter seasons is larger, the smaller fluctuations in the spring, and the loss of sediment in autumn and winter is greater than that in spring.

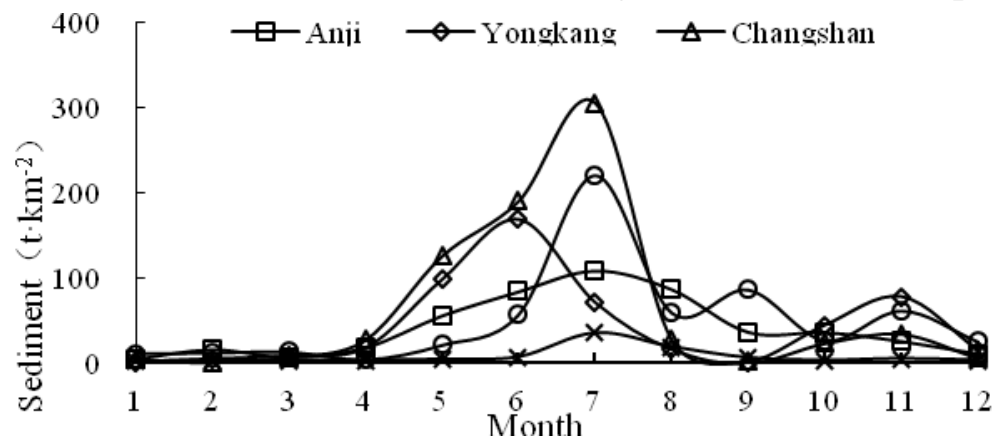

Fig.4 Monthly sediment yield characteristics in different regions

\section{Relationship Between Rainfall, Runoff and Sediment Yield}

Analysis of rainfall and runoff found (Fig. 5), runoff increased with the increase of rainfall, and decreased with the decrease of rainfall, it showed that there are some relationships between the two. This is mainly due to rainfall is the main source of runoff generation, if the larger rainfall, the resulting runoff will be relatively large. The same to the runoff and sediment yield analysis (Figure 
6), found that the amount of sediment loss with the flow of the fluctuations and fluctuations, and the law of variation of runoff is consistent, there is a certain relationship between the two. This is mainly due to rainfall caused by surface runoff soil erosion, rainfall will surface soil stripping, the formation of rain splash erosion, runoff is responsible for the stripping of soil particles migration away. Therefore, the sediment loss increases with the increase of runoff.

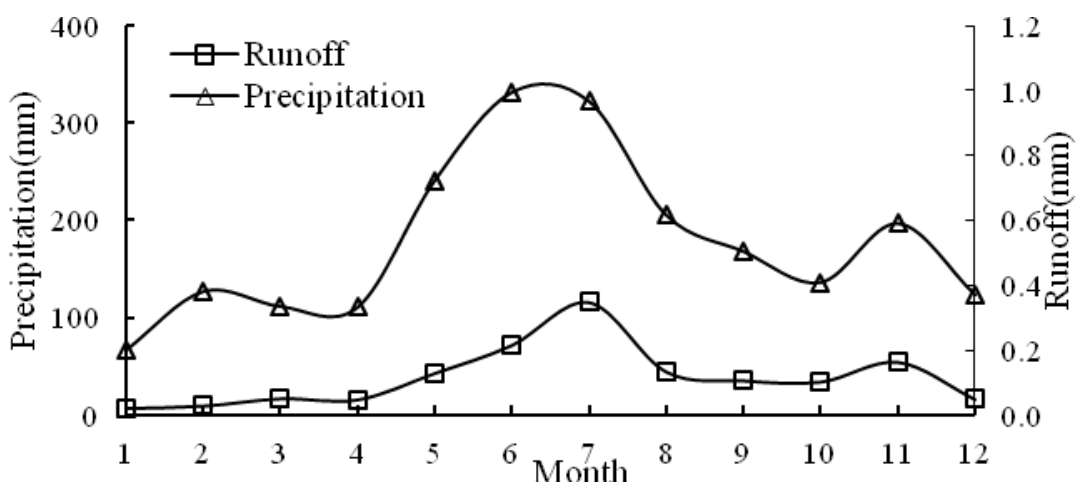

Fig.5 Relationship between runoff and rainfall

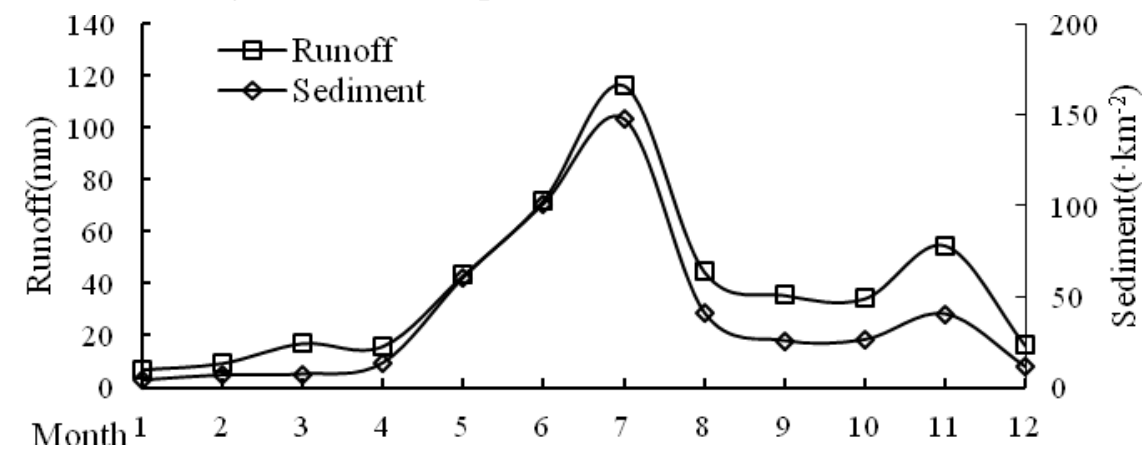

Fig.6 Relationship between runoff and Sediment

\section{Conclusion}

(1) in 2015, the total amount of rainfall in 5 regions of Zhejiang province was between $1716.0-2834.5 \mathrm{~mm}$, and the amount of rainfall was abundant. Rainfall mainly concentrated in 4-9 months, accounting for $60.7 \%-66.6 \%$ of the annual rainfall. Total rainfall from large to small: Yuyao $>$ Changshan $>$ Anji $>$ Yongkang $>$. The four seasons of rainfall, the second and third quarter reached the maximum, first and fourth quarter is relatively small.

(2) the total annual runoff from large to small: Yongkang > Changshan > Yuyao > Anji. And runoff mainly concentrated in 5-9 months, accounted for $67.4 \%-76.2 \%$ of the annual runoff. Runoff in autumn and winter seasons, the larger fluctuations in the spring, and the smaller fluctuations, and the autumn and winter runoff is greater than the spring. Annual sediment loss from large to small: Yuyao > Yongkang > Anji > rooftop. The amount of sediment loss is mainly concentrated in 5-9 months, which accounts for $68.3 \%-86.7 \%$ of the annual runoff. Also in the autumn and winter seasons, fluctuations in the larger, smaller fluctuations in the spring, and the loss of sediment in autumn and winter than in spring.

(3) of rainfall and runoff, runoff and sediment analysis, runoff with rainfall fluctuations, sediment loss fluctuate with runoff fluctuation, that runoff and rainfall, runoff and sediment loss of.

\section{Acknowledgements}

This work was financially supported by Natural Science Foundation of Zhejiang Province of china(Grant No. LY14E090005), Department of Science and Technology of Zhejiang Province(Grant No. 2014F50015). 


\section{Reference}

[1] Liu Qiang. Study on Soil and water conservation planning of Anji County, Zhejiang province [D]. Northwest Agriculture and Forestry University, 2015

[2] Bi H X, Liu B, Wu J, et al.Effects of precipitation and Landuse on runoff during the past in a typical watershed 50 years in the loss plateau, China [J]. International Journal of Sediment Research, 2009, 24 (3): 352-364.

[3] Li Guang, Huang Gaobao. Effects of rainfall intensity and land use on Soil and water loss in Loess Hilly Region [J]. Journal of agricultural engineering, 2009, 25 (11): 85-90. 